


\title{
PROPOSTA DE SOCIALIZAÇÁO AMBIENTAL PARA AS COMUNIDADES DO JARDIM GIANNA I E II NA CIDADE DE PONTA GROSSA (PARANÁ, BRASIL)
}

\author{
PROPOSAL FOR ENVIRONMENTAL SOCIALIZATION FOR THE \\ COMMUNITIES OF GARDEN GIANNA I AND II \\ IN THE CITY OF PONTA GROSSA (PARANÁ, BRAZIL)
}

J. P. L. de Almeida ${ }^{1}$, J. A. Prandel ${ }^{1} \&$ A. S. Uller ${ }^{2}$

\begin{abstract}
Resumo - Vários trabalhos disseminam a consciência ambiental pelo mundo, no entanto, estes já não proporcionam os efeitos esperados na sensibilização das pessoas. Talvez por motivo de açóes individualizadas ou em pequenas escalas, procurando englobar grandes regióes. Assim, a proposta do trabalho aqui apresentado objetiva mobilizar lideranças representativas do bairro Gianna (Ponta Grossa-PR-BR), para que exerçam ações junto aos demais indivíduos que fazem parte da comunidade, sensibilizando a todos quanto à necessidade de evitar atitudes contrárias ao meio ambiente, e assim sucessivamente até alcançar espacialidades maiores em uma temporalidade contínua. Além de atuar diretamente com os representantes sociais, a proposta demanda também atitudes conjugadas com o Poder Público, instituiçóes privadas, ONG's, instituiçôes de ensino e da comunidade do entorno, em prol da recuperação e preservação do meio ambiente local. Os resultados obtidos até o momento ainda se encontram em patamares de uma ação incubadora, onde as lideranças estão sendo contactadas e convidadas a participar de reunióes de grupo para traçar diretrizes operacionais. Estima-se que no mês de março, será possível estabelecer os primeiros contatos entre lideranças e comunidade, onde serão efetivadas práticas de sensibilização e elaboração de projetos a serem enviados ao poder público no sentido de solicitar implementaçóes de melhoria às condiçôes ambientais presentes. O projeto incentivará ações de fiscalização pela própria comunidade, condicionando cada sujeito ao bom uso do ambiente comum, pois
\end{abstract}

\footnotetext{
${ }^{1}$ Bacharelandos em Geografia, Universidade Estadual de Ponta Grossa (UEPG), Paraná, Brasil; jessicaprandel@ hotmail.com; jpl_almeida@yahoo.com.br

${ }^{2}$ Pesquisadora do Departamento de Geociências. Universidade Estadual de Ponta Grossa (UEPG), 32203046. Paraná, Brasil; adri.uller@yahoo.com.br; aliccardo@uepg.br
} 
de nada adianta ações mitigatórias sem esclarecimento da importância da participação individual na preservação local.

Palavras-chave - Representação social; mobilização preservacionista; meio ambiente

Abstract-Several works spread environmental awareness around the world, however, they no longer deliver the expected effects in people's awareness. Maybe this is due to individualized actions or in small scales, seeking to cover large areas. Thus the proposal of the work presented here aims to mobilize leaders representing the neighborhood Gianna (Ponta Grossa - PR-BR), for carrying out actions with other individuals who are part of the community, raising awareness to everyone about the need to avoid attitudes against the environment, and so on until it reaches a wider audience and continuous temporality. In addition to acting directly with social representatives, the proposal also demand conjugation with the Public attitudes, private institutions, NGOs, educational institutions and the neighbor community, in favor of the recovery and preservation of the local environment. The results obtained so far are still in levels of incubator action, where the leadership are being contacted and invited to participate in group meetings for the sketch of the operational guidelines. It is estimated that in the month of March, it will be possible to establish the first contacts between leaders and the community, which will be effective awareness-raising practices and elaboration of projects to be submitted to public authorities in order to request improvement implementations to present environmental conditions. The project will encourage enforcement actions by the community, thus controlling each citizen to proper use of the common environment, as mitigating actions without clarification of the importance of individual participation in site preservation are useless.

Keywords - social representation; mobilisation of environmental preservation; environment

\section{1 - Introdução}

Nas condiçóes do mundo contemporâneo a necessidade de preservação não se remete apenas ao ambiente natural, havendo cada vez mais a busca incessante de recuperar áreas que perderam uma grande parte de suas características originais, ainda que ocupadas socialmente. Tal situação penosa se intensifica no espaço urbano ${ }^{3}$ (CORRÊA, 2003), onde se vê aumentadas as dificuldades de restabelecimento da paisagem natural, por necessidade de projetos urbanísticos e arquitetônicos que náo mantêm as características peculiares da vegetação do referido espaço físico em prol de alojar uma infraestrutura adequada às necessidades de implementaçóes das diversas açôes humanas.

3 “(...) conjunto de diferentes usos da terra justapostos entre si. Tais usos definem áreas, como o centro da cidade, local de concentração de atividades comerciais, de serviços e de gestão, áreas industriais,áreas residenciais distintas em termos de forma e conteúdo social, de lazer e, entre outras, aquelas de reserva para futura expansão" (CORRÊA., 2003, p. 7). 
Assim, é notório afirmar que atividades antrópicas são as responsáveis pela degradação do ambiente natural e a descaracterizaçáo do mesmo, porém é preciso refletir sobre quais questóes são as causas dessa falta de consciência humana, e como é possível reverter tal quadro caótico dos dias atuais.

A realidade de problemas ambientais se instala não apenas nas grandes potências econômicas mundiais, que vivem em uma correria frenética de avanços produtivos, mas também, nas instâncias dos países subdesenvolvidos que sofrem com a pobreza, ou que se encontram numa situação emergente, em luta por um desenvolvimento mais expressivo.

Tais situaçóes preocupantes têm mobilizado organismos do mundo inteiro, desde a Conferência de Estocolmo em 1972, e posteriormente na Rio 92, que tratou de organizar uma agenda com açóes focadas num desenvolvimento sustentável para todas as naçóes, visando salvaguardar riquezas naturais, que se encontram em situação de risco, para que possam também ser usufruídas pelas futuras geraçóes.

No Brasil, palco deste último evento ambientalista mundial, algumas políticas públicas foram implantadas em prol dessa finalidade de se preservar o meio ambiente, porém, percebe-se que ainda está muito longe de se concretizar um ideal de desenvolvimento sustentável, pois as açóes não alcançam as comunidades menos envolvidas nos ditames do poder público.

Assim, buscando contribuir de modo singelo, mas efetivo esta pesquisa voltou-se para um recorte espacial mais localizado, o Bairro Giana, localizado no município de Ponta Grossa-PR, com o seguinte objetivo: mobilizar lideranças representativas do bairro Gianna (Ponta Grossa-PR-BR), para que exerçam papéis consolidados sobre os demais indivíduos que fazem parte da comunidade, sensibilizando a todos quanto a necessidade de evitar as atitudes contrárias ao meio ambiente, de modo a preservá-lo, e fazendo com que isso sucessivamente alcance espacialidades maiores em uma temporalidade contínua.

Tal procedimento foi traçado de forma em que fosse possível acompanhar todos os passos da ação desenvolvida diretamente com a comunidade através de suas lideranças de bairro.

O primeiro passo realizado foi fazer um reconhecimento das condiçóes locais, através de um minucioso trabalho de campo, onde foi possível constatar que houve um aumento considerável no lançamento de resíduos sólidos nas proximidades de afluentes que se encontram nas comunidades do Jardim Giana I em II (imagem 1) na cidade de Ponta Grossa - PR. Posteriormente, buscou-se contato com demais repartiçóes da sociedade, para encontrar parcerias essenciais.

A primeira instituição envolvida foi o Rotary Club de Ponta Grossa (Sabará), onde foi apresentado o levantamento realizado sobre as condiçóes do bairro Giana (I e II) e discutidas possibilidades de intervenção para reverter o quadro de degradação e estabelecer açóes preservacionistas. $\mathrm{Na}$ discussão ficou claro que seria necessária a participação de outros segmentos do poder público, no sentido de financiar despesas e/ou realizar operaçóes que demandam serviços de limpeza e recuperação de áreas em situaçóes emergenciais. Também foi acordado que alguns investimentos poderiam vir de instituições privadas, e ainda que a principal atuação seria frente à comunidade, de modo a conscientizar a cada um do seu papel na manutenção do equilíbrio ambiental 
das espécies locais, e ainda, que os espaços públicos sendo de todos, cabendo a cada um o dever de agir e protegê-lo.

$\mathrm{Na}$ instância comunitária, foi pensada uma atuação através das lideranças de bairro, que podem organizar de forma mais eficaz os grupos de moradores para estabelecer diálogos e açôes necessárias. Para atingir os jovens da comunidade, o papel das escolas, igrejas e instituiçóes sociais (como o Rotary), poderia contribuir no envolvimento destes, desde pequenos, para formar a consciência preservacionista desde as idades mais tenras.

O desenvolvimento que segue traz alguns referenciais teóricos pertinentes ao trabalho e descreve com detalhe as etapas do projeto e o que já fora desenvolvido.

\section{2 - Reconhecimento da área e problema de pesquisa-ação}

As comunidades do Jardim Gianna I e II estão localizadas na região norte da cidade de Ponta Grossa - Paraná, com cerca de 2.220 pessoas, que habitam 565 residências (Fig. 1). Por serem comunidades relativamente novas (PMPG, 2011) ${ }^{4}$, estas refletem o crescimento da cidade que nos últimos dois anos, obteve cerca de cinco mil novas construçóes regulamentadas (CREA, 2011) $)^{5}$.

O local em questão tornou-se estímulo de investigação e atuação quando, em uma breve investigação de campo realizada em setembro de 2011, percebeu-se uma enorme quantidade de resíduos sólidos lançados indevidamente nas proximidades de um regato na comunidade do Jardim Giana I em um curto período de tempo (4 meses), tendo como base um comparativo com imagens de outro levantamento hidrográfico da região, efetuado para o Rotary Clube Ponta Grossa - Sabará, feito em maio de 2011, pelo presidente do clube citado, podendo ser observada a descaracterização da paisagem na comparação das Figs. 2 e 3.

A partir dessa constataçáo foram executadas novas saídas a campo para a identificação e classificação dos resíduos, podendo ser verificado que a maior parte dos resíduos eram constituídos de sobras provenientes da construçáo civil (Fig. 4), uma vez que esta regiāo é caracterizada no processo de urbanização recente, com um notável crescimento habitacional.

Mesmo diante da identificação de tais resíduos de construção civil ali depositados, não podemos desconsiderar os demais resíduos advindos de outras atividades, que de uma forma ou de outra exercem influência na descaracterização da paisagem.

\footnotetext{
${ }^{4}$ Dados adquiridos juntamente a Prefeitura Municipal de Ponta Grossa, com o processo no 2690089/2011. O loteamento Jardim Giana I foi aprovado pelo DECRETO No 571 de 05/12/2002 (revogado pelo DECRETO 56/2003) e o loteamento Jardim Giana II teve sua aprovação com o DECRETO no 572 de 05/12/2003 (revogado pelo DECRETO no 57/2003).

5 Visitado em 19/10/2011; http://www.diariodoscampos.com.br/geral/noticias/38704/?noticia=crea-aponta-aumento-da-construcao-civil-em-pg em publicação onde o CREA (Conselho Regional de Engenharia, Arquitetura e Agronomia) coloca que houve um aumento da construção civil em Ponta Grossa - Paraná.
} 
Localização e dados da área de implantação do projeto.

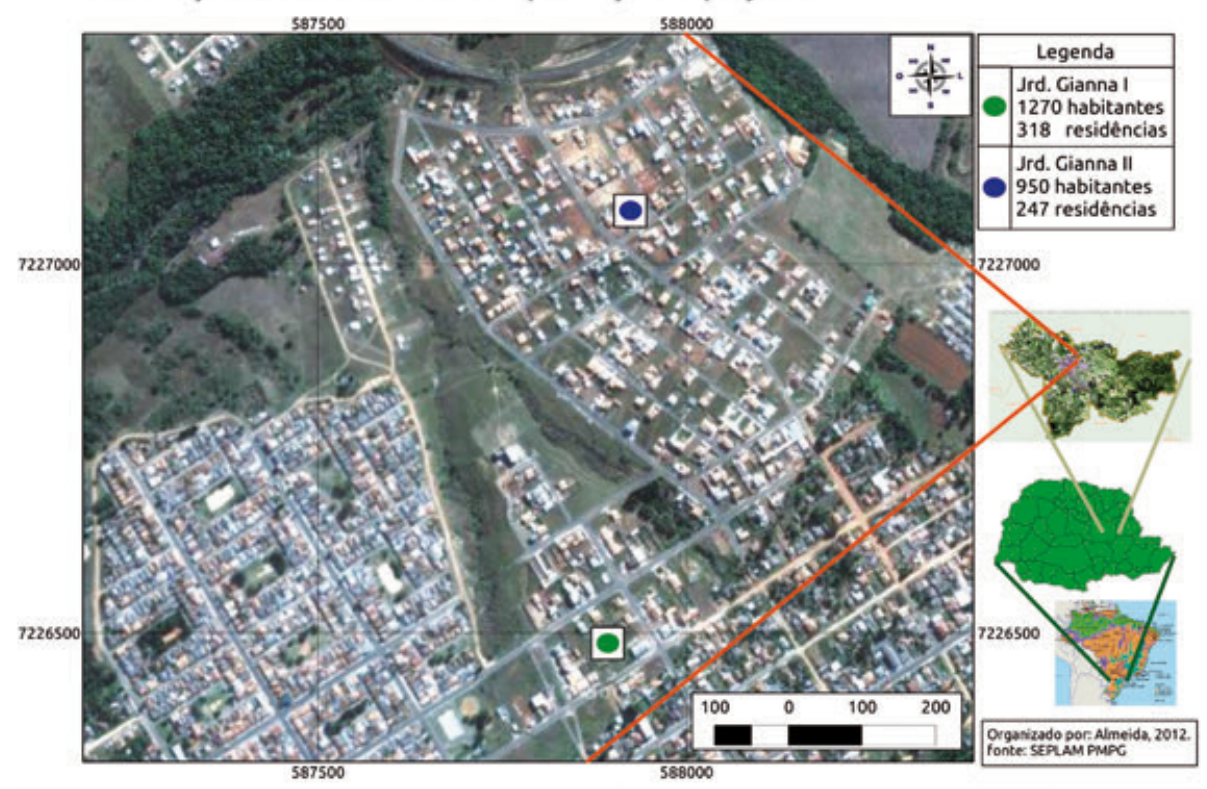

Fig. 1 - Localização do bairro Jardim Gianna (I e II). (ALMEIDA, 2011).

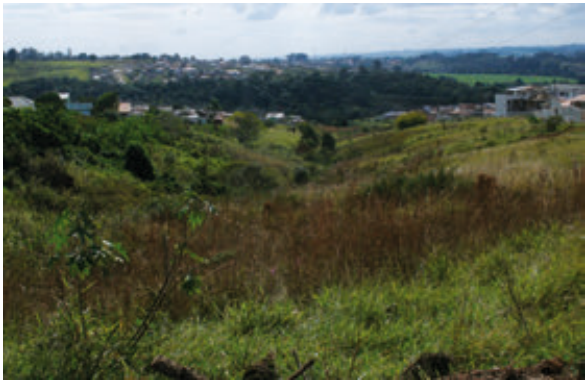

Fig. 2 - Estado do Arroio em 05/2011 (ALMEIDA, 2011).

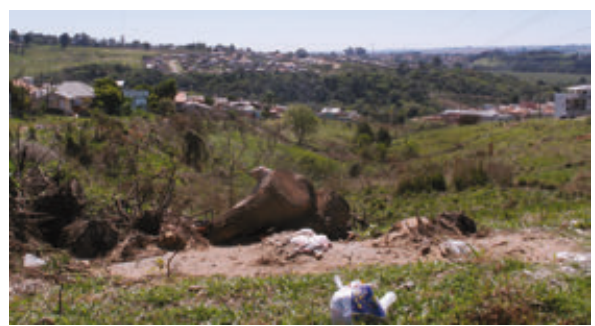

Fig. 3 - Estado do Arroio em 09/2011 (ALMEIDA, 2011).

A paisagem em sua dinâmica temporal se remodela naturalmente, pelos processos de intemperismo, erosão e deslizamentos (FERNANDES \& AMARAL, 2000), carregando materiais de origem natural ou antrópica da parte alta da encosta para sua base (como no caso um afluente do Arroio Piláo de Pedra), e com tais agressóes poluidoras, perdem o seu mecanismo próprio, tomando novos direcionamentos, muitas vezes acelerados pela invasão dos resíduos antrópicos.

Contudo, este acúmulo de detritos identificados como sendo de construção civil ferem as normas ditadas pelo Plano integrado de gerenciamento de resíduos da construçáo civil do município de Ponta Grossa, aprovado pelo DECRETO no 1111 de 17/08/2006 
que tem como objetivo "estabelecer diretrizes, critérios e procedimentos para a gestão dos resíduos da construção civil, disciplinando as ações necessárias de forma a minimizar os impactos ambientais". Daí o questionamento sobre para que servem as normas se estas não são seguidas e nem mesmo fiscalizadas.

Independentemente da origem dos materiais, o acúmulo de resíduos proporciona a proliferação de microrganismos que são vetores de uma grande quantidade de doenças. Alguns destes microorganismos são ingeridos diariamente pelos humanos, causando-lhes infecçóes imperceptíveis. Outros transmissores como a mosca domésticas e uma variedade de espécies de baratas, estáo associados a mais de 45 doenças; febre tifoide, disenterias, amebíase, poliomielite, gastroenterites ... (PEREIRA NETO, 2007 p. 25). Algumas vezes, por precauçóes sanitárias, estas açôes no corpo humano são inibidas por anticorpos adquiridos pelas vacinas, porém não se pode curar problemas de grande monta apenas por meios paliativos, tem-se que agir na raiz do problema que é o acúmulo de lixo e a degradação ambiental, sendo esta a melhor forma de controle das calamidades, reduzindo assim os gastos com saúde.

Outra influência consequente do depósito irregular dos residuos sólidos esta nos movimentos de massa, segundo a MINEROPAR (2011) ${ }^{6}$, é um "fenômeno de escorregamento de um maciço (solo ou rocha) em superfície inclinada (talude), devido a várias causas." Também chamado de deslizamento, tendo como fator de maior importância a declividade, neste fenômeno à ação da força da gravidade. No entanto, esta é acelerada pelo tipo de uso do solo e pela infiltração excessiva de água proveniente de chuvas torrenciais.

Dentre outros pesquisadores, Márcio Túlio Miranda coordenador de áreas de risco geológico da Defesa Civil de Salvador - $\mathrm{BA}^{7}$ relata que "o lixo facilita o deslizamento porque além de ser matéria agregada, retém umidade no solo, facilita o encharcamento e potencializa o risco de deslizar".

Os casos de movimentos de massa na parte urbana da cidade de Ponta Grossa são constantes, por obter áreas com declividades acentuadas e a ação antrópica que em boa parte desconhece os riscos. Em proporçôes, no momento menores, há casos no Jardim Giana (figura 5), que com cobertura vegetal adequada pode reduzir as ocorrências, evitando movimentos maiores.

\footnotetext{
${ }^{6}$ Serviço Geológico do Paraná.

7 Em entrevista ao Jornal da Tarde de Salvador.
} 

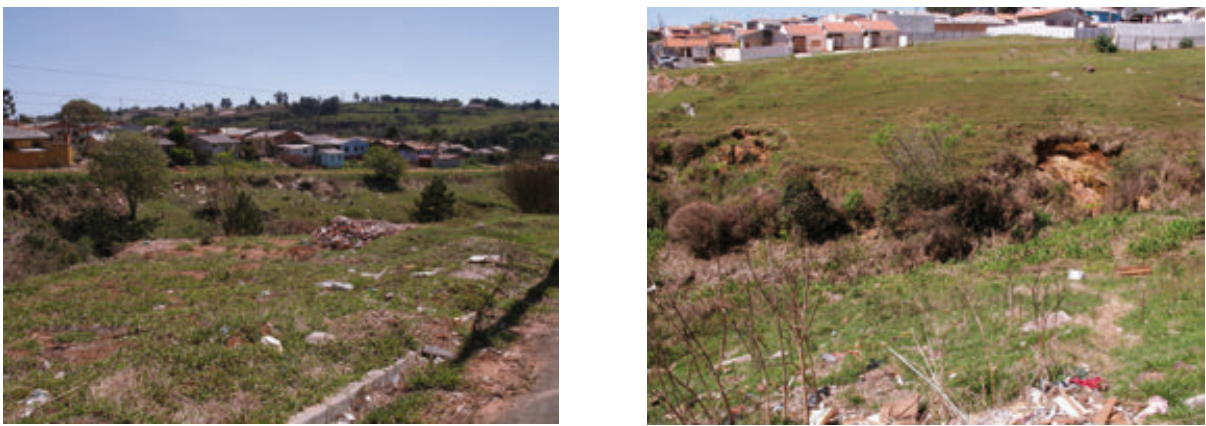

Fig. 4 e 5 - Resíduos de construção civil ocupam o terreno vazio (foto 4) e movimento de massa sendo contido pela vegetação (foto 5) (ALMEIDA, 2011).

Diante dos problemas constatados, a literatura torna-se de fundamental importância para a compreensão de como isso é visto por outros pesquisadores e também por órgãos do poder público que tem preocupaçóes afins.

\section{3 - Debatendo a problemática com a teoria de estudo}

A problemática em questão está focada nas deliberações de órgãos ambientalistas locais, regionais e nacionais como IAP (Instituto Ambiental do Paraná), IBAMA (Instituto Brasileiro de Meio Ambiente e Recursos Naturais Renováveis), CONAMA (Conselho Nacional do Meio Ambiente), que atuam no controle ambiental de diferentes áreas buscando uma melhor atuação do ser humano com o meio ambiente. Para tanto, fica claro que se fazem necessárias medidas emergenciais capazes de fortalecer a atuação das pessoas, profissionais ou leigas, de maneira individual ou coletiva, em prol do meio ambiente sustentável.

Abordando a situação, procuramos a definição de resíduos sólidos, que para a Associação Brasileira de Normas Técnicas, com a NBR 10004 assim define (ABNT, 2004): "Resíduos nos estados sólido e semi-sólido, que resultam de atividades de origem industrial, doméstica, hospitalar, comercial, agrícola, de serviços e de varrição. Ficam incluídos nesta definição os lodos provenientes de sistemas de tratamento de água, aqueles gerados em equipamentos e instalaçóes de controle de poluição, bem como determinados líquidos cujas particularidades tornem inviável o seu lançamento na rede pública de esgotos ou corpos de água, ou exijam para isso soluçóes técnica e economicamente inviáveis em face à melhor tecnologia disponível."

Alguns autores utilizam a denominação de "lixo" para o material proveniente da atividade humana, como é o caso de PEREIRA NETO $(2007)^{8}$ inserindo em seu trabalho que "a tipologia do lixo é definida de acordo com o local em que é gerado". Diferentemente da definição do SEMA (2008)9 (Secretaria de Estado do Meio Ambiente e Recursos Hídricos), lixo é "Tudo que náo pode ser reaproveitado ou reciclado".

${ }^{8}$ Logo em sua introdução insere que “O homem estabeleceu, há muitos anos, que 'lixo' é todo e qualquer tipo de resíduo sólido resultante de sua atividade’

9 Desperdício Zero pág.09 
Saindo dos conflitos conceituais, independe da denominação, todo o resíduo lançado na natureza sem um tratamento adequado agride e deteriora o meio ambiente e seus componentes de extrema necessidade para vida humana como a água, o solo, o ar, etc.

$\mathrm{Na}$ caracterização dos resíduos encontrados nas encostas do Jardim Giana, a maior parte provém de obras da construção civil, sem desconsiderar os de outra origem que aparentemente agem de diferente forma (físico, química e biológica) na modificação da paisagem. Composto por uma grande quantidade e variedade de resíduos, denominados de entulho os originados nas obras civis em grande parte cerca de $90 \%$ podem ser reciclados (SEMA, 2008, p.180).

Quanto à diversidade o CONAMA (2002) Conselho Nacional do Meio Ambiente na Resolução 307/02 institui, classifica e frisa que a responsabilidade sobre os resíduos provenientes da construção civil é dos geradores, independente da quantidade gerada, seja por construção ou demolição, inserindo ainda que "os geradores deverão ter como objetivo prioritário a não geração de resíduos e secundariamente, a redução, a reutilização, a reciclagem e a destinação final.” Independente de onde, esta assertiva regra deve ser aplicada nas açóes de todos.

\section{4 - O desenvolvimento do trabalho}

Primeiramente, após detectada a problemática da pesquisa verificou-se que para uma proposta como esta, de não ser apenas investigação, mas seguisse a "Metodologia da pesquisa ação" (THIOLLENT, 1947) a principio a mais adequada para a situação, tendo que, com o amadurecimento metodológico adequado, é possível dar ênfase a "resolução de problemas, tomadas de consciência e produção de conhecimento". Tal proposta demandaria contudo um esforço no sentido prático, pois ao se trabalhar com a comunidade, os objetivos devem ser claros e com açóes contínuas, para que realmente seja possível alcançar resultados concretos.

Também foi constatado que seriam necessárias açóes de parcerias com o Poder Público, empresas privadas e ONG's (DOWBOR \& TAGNIM, 2005) ${ }^{102}$, com fim de obter apoio das várias formas cabíveis. A divulgação da proposta poderia se dar de forma indireta, onde os mesmos moradores seriam informados por sua representaçáo social (representantes de bairro), que por sua vez, acompanharia a retirada dos resíduos sólidos, que encontram-se em locais indevidos.

Assim, as saídas a campo para observação tiveram extrema importância para que este projeto fosse realizado e como já fora citado, a principal alavanca para efetuar o levantamento foi efetuado pelo presidente do Rotary Clube Ponta Grossa - Sabará, Sr. Lourival A. Góis, que apoia em todos os sentidos a realização de tais açóes. Em conversa informal com moradores das comunidades em questão foi possível observar a necessidade de uma maior participação dos mesmos nas atitudes que tem como propósito melhorar a convivência das pessoas que ali moram com o meio.

Pela impossibilidade de reunir toda a comunidade foi efetuada uma seleção pelos moradores, através de entrevista formal, indicando representantes sociais da comunidade.

102 DOWBOR, 2005 coloca que; "A articulação dos três setores (Estado, empresas e ONGs), em parceria reflete uma sustentação mais radicalizada em termos de fomento para o processo de educação de uma sociedade." 
Segundo ARRUDA (2002) "representação social é um modo de conhecimento sociocêntrico, que segue as necessidades, os interesses e desejos do grupo...”, estes então defenderão as necessidades dos moradores.

Nas próximas semanas, um evento integrando os representantes da comunidade será realizado, simultaneamente com a coleta dos resíduos que se encontram nas proximidades dos córregos, sendo esta efetuada pela empresa de limpeza pública do município. O espaço para realizaçáo dos eventos será cedido pelo Rotary Clube Ponta Grossa - Sabará, conhecido como "Casa da Cidadania”. Para direcionar os olhares dos integrantes, com especialistas da área será efetuada uma palestra sobre o meio ambiente e a falta que este pode fazer.

Ao fim desta será executado uma dinâmica de grupo onde os representantes serão divididos em grupos de até 10 (dez) componentes e aplicados os seguintes questionamentos;

1. Qual o ponto fraco da relaçáo da comunidade com o meio ambiente?

2. Qual o ponto forte da relação da comunidade com o meio ambiente?

3. Atividades que realizamos hoje, mas não deveriam ser realizadas para melhorar a relação da comunidade com o meio ambiente?

4. Atividades que náo realizamos hoje, que deveriam ser realizadas para melhorar a relação da comunidade com o meio ambiente?

5. Qual a sua sugestão para melhorar a relação da comunidade com o meio ambiente?

Todas as questôes serão aplicadas para cada grupo e para cada questão deve ser atribuída 5 (cinco) respostas e destas as 3 (três) que mais aparecerem entre todos os grupos e para cada questão, serão destacadas pelo grupo da organização para divulgação dos resultados ao final. A aplicação das questôes seguirá a sequência e ao final de cada, haverá o recolhimento das respostas, a serem tabuladas e analisadas.

Tendo como resultado "defeitos e qualidades da relação da comunidade com o meio ambiente", serâo apontados indicadores para onde tem maior necessidade de mudanças, além de propostas que deveráo modificar a atitude dos participantes ou ainda atitudes que terão de ser tomadas pelo Poder Público, estas por sua vez serão protocoladas na PMPG e verificadas cotidianamente as açôes que forem tomadas.

Os efeitos da dinâmica de grupo terão de ser repassado ao maior número de populares e os resultados serão divulgados na imprensa aberta ( $\mathrm{TV}$, radio e jornais) para obter melhores resultados, demonstrando a efetiva participação dos sujeitos envolvidos, como reais cidadáos participantes e construtores de sua sociedade e seu espaço de vivência.

Posterior aos acontecimentos estudos mais aprofundados da área serão efetuados e novas açôes terão de ser tomadas como; o replantio de espécies nativas, inserção de caçambas adaptada para a coleta dos resíduos provenientes da construção civil, manutenção dos resultados alcançados e eventos anuais com a comunidade e possível disseminação da ação para outras comunidades, com o propósito de expandir sucessivamente o trabalho.

É importante salientar que toda ação será seguida da análise dos resultados obtidos melhorando e/ou modificando o passo seguinte. Neste estão descritas apenas os passos iniciais, o que não podem ser tomados como exatos, nem ainda como únicos. A continuidade das açôes ao trabalhar com a comunidade, tem extrema importância para a eficiência e eficácia dos resultados. 


\section{5 - Conclusão.}

Realizar pesquisa acadêmica de cunho ambiental e social traz para os sujeitos muita satisfação, e quando esta pode ser atrelada a práticas de mobilizações, por mínimas que sejam, repercutem em maiores prestígios profissionais, pois é possível visualizar nma prática os resultados aferidos.

Este trabalho ainda está no meio do percurso, porém visualiza-se possibilidades promissoras, com o envolvimento de diferentes instituiçóes que manifestaram apoio à esta proposta.

Em contato com o Poder Público, através da Secretária do Meio Ambiente de Ponta Grossa dispuseram de número de telefone e endereço de e-mail para denúncia contra as irregularidades, que já é de grande apoio à proposta. No entanto acreditamos que a facilitação na destinação final correta dos resíduos pertinentes, através da coleta efetivada de imediato terá maior apoio e menos impacto com os sujeitos que praticam os lançamentos irregulares, e é preciso realizar com estes um embate paciente e cauteloso.

$\mathrm{O}$ apoio das instituiçôes privadas situadas na regiáo será menos penoso quando demonstrada a necessidade e apoio popular. Acreditamos ganhar credibilidade na soma de esforços, comunidade+pesquisadores+lideranças+poder público.

Também a colaboração do Departamento de Geociência da Universidade Estadual de Ponta Grossa (UEPG) está sendo de grande pertinência, na medida em que oportuniza o diálogo reflexivo entre os acadêmicos e profissionais especializados, e amplia o rol de referenciais teórico-metodológicos para fortalecer o trabalho.

Desenvolver atividades com as instituiçôes de ensino da comunidade e do seu entorno disseminando a importância da preservação ambiental entre as crianças e os adolescentes, possibilitará a continuidade das atitudes para o desenvolvimento da comunidade com consciência ambiental.

\section{Referências Bibliográficas}

ABNT (2004) - NBR 10004, Resíduos sólidos - Classificação.

ALMEIDA, J.P.L. (2011) - Imagens gerais. In Dados preliminares da pesquisa: Ponta Grossa.

ARRUDA, Angela (2002) - Teoria das Representaçóes Sociais e Teorias de Gênero in Caderno de Pesquisa. Rio de Janeiro: No 117 , p. 127 - 147.

CONAMA (2002) - Gestão dos resíduos da construçấo civil. Resoluçấo 307 de 05/07/02 do CONSELHO NACIONAL DO MEIO AMBIENTE (CONAMA). Disponível em; www.meioambiente.pr.gov.br/modules/conteudo/print.php?...5 (consultado em; 2011/11/01).

CORRÊA, R. L. (2003) - O espaço urbano. São Paulo: Ática.

CREA (2011) - DIÁRIO DOS CAMPOS; consideraçôes do CREA (Conselho Regional de Engenharia, Arquitetura e Agronomia) disponível em; http://www.diariodoscampos.com.br/geral/noticias/38704/?noticia=crea-aponta-aumento-da-construcao-civil-em-pg, (consultado em; 19/10/2011).

DOWBOR, L. TAGNIM. R. A. (2005) - Administraçấo da água, como se fosse importante. São Paulo: Ed. Senac,.

FERNANDES, N. F. \& AMARAL, C. P. (2000) - Movimento de massa: uma abordagem Geológico-Geomorfológica/ cap. 3 in Geomorfologia e Meio Ambiente organizado por GUERRA, A.J.T. CUNHA, S. B. $3^{\circ}$ ed. Rio de Janeiro: Beltrand Brasil, p. 124 
SEMA (2008) - Desperdício zero: Programa da Secretaria de Estado do meio ambiente e recursos hídricos. Governo do Paraná, SEMA. Curitiba-PR, 2008.

PEREIRA NETO. J. T. (2007) - Gerenciamento do lixo urbano: aspectos técnicos e operacionais. Viçosa, MG: Ed. UFV,.

PMPG (2011) - PREFEITURA MUNICIPAL DE PONTA GROSSA, Secretaria Municipal de planejamento com o processo no 2690089/2011 juntamente com os DECRETOS no 571/2002 e 572/2002. Ponta Grossa: 2011.

, DECRETO no 1111, de 17/08/2006. disponível em; geo.pg.pr.gov. br/portal/planodiretor/raalanexo3.pdf acesso em: 11/11/2011

MINEROPAR (2011) -. Glossário de termos geológicos. Serviço Geológico do Paraná - Mineropar . http:// www.mineropar.pr.gov.br/modules/glossario/conteudo.php?conteudo=A acesso em: 17/11/2011.

THIOLLENT, Michel (1947) - Metodologia da Pesquisa-ação. $18^{\circ}$ ed. 2011, São Paulo: Cortez.

Resíduos nos estados sólido e semi-sólido, que resultam de atividades de origem industrial, doméstica, hospitalar, comercial, agrícola, de serviços e de varrição. Ficam incluídos nesta definição os lodos provenientes de sistemas de tratamento de água, aqueles gerados em equipamentos e instalaçóes de controle de poluição, bem como determinados líquidos cujas particularidades tornem inviável o seu lançamento na rede pública de esgotos ou corpos de água, ou exijam para isso soluçóes técnica e economicamente inviáveis em face à melhor tecnologia disponível. 